\title{
OPEN $\left(\mathrm{Cu}_{2} \mathrm{O}-\mathrm{Au}\right)$ - Graphene - Au layered structures as efficient near Infra - Red SERS substrates
}

\begin{abstract}
Radhika V. Nair (i) \& V. M. Murukeshan*
Near Infra-Red Surface Enhanced Raman Spectroscopy (NIR SERS) has gained huge attention in recent years as the conventional visible SERS suffers from overwhelming fluorescence background from the fluorophore resulting in the masking of Raman signals. In this paper, we propose a novel multilayered SERS substrate- $\left(\mathrm{CU}_{2} \mathrm{O}\right.$ - $\left.\mathrm{AU}\right)$ - Graphene - $\mathrm{AU}$ - for efficient NIR SERS applications. The proposed structure has a monolayer of $\mathrm{Cu}_{2} \mathrm{O}$ - Au core-shell particles on a Au substrate with $1 \mathrm{~nm}$ thick graphene spacer layer. Mie simulations are used to optimize the aspect ratios of core-shell particles to shift their plasmon resonances to NIR region using MieLab software. Further, Finite Difference Time Domain (FDTD) simulations using Lumerical software are used for the design of the multiparticle layered SERS substrate as MieLab software works only for single particle systems. Designed structure is shown to provide high field enhancement factor of the order of $10^{8}$ at an excitation of $1064 \mathrm{~nm}$ thus ensuring the possibility of using the proposed structure as efficient NIR SERS substrate which could probably be used for various NIR sensing applications.
\end{abstract}

Rapid growth in biosensing and bioimaging research fields in the recent past involved potential development of novel nanostructured materials and various imaging techniques that involved optical probes, specialty fiber optics, Surface Enhanced Raman Spectroscopy (SERS) ${ }^{1-5}$. Out of these, SERS was used in the trace analysis of various chemicals, finding potential applications in fields such as biochemistry, medical diagonostics, food contamination detection, water safety, trace level explosive detection and forensics ${ }^{6}$. Raman signals of the analyte molecules get enhanced in SERS by the amplification of light due to the generation of localized surface plasmons in the gaps and sharp edges of metallic nanoparticles, micro or nanopatterned structures or on the roughened metallic surfaces ${ }^{7-10}$. Large enhancement in Raman signals is achieved when the plasmon resonance wavelength almost matches with the excitation wavelength which generally falls within the visible to NIR region (400 to $850 \mathrm{~nm})^{11}$. Visible light excitation in SERS may result in photobleaching, plasmonic heating and also in an overwhelming fluorescence background as most of the fluorophore analytes have strong emission within the visible region resulting in the masking of Raman signals ${ }^{12}$. These problems can be overcome by using larger wavelength excitations (NIR lasers) ${ }^{13}$. Tunability in plasmon resonances to match with the exciation wavelength can be achieved by the modification of metallic or metal hybrid nanoparticle morphologies or using core-shell particles $^{14}$. Different metal-dielectric, dielectric-metal, metal-metal and multilayer metal-dielectric structures are shown to have large tunability of plasmon resonances from visible to NIR region ${ }^{15,16}$. Various imaging techniques can be used for nanoscale level imaging of such structures ${ }^{17,18}$. Plasmonic resonances of core-shell particles are highly sensitive to core radius, shell thickess and refractive indices of core and shell ${ }^{19}$. High refractive index dielectric core enables efficient coupling between spherical and cavity plasmons leading to large tunability of symmetric modes (longer wavelength modes) ${ }^{20} . \mathrm{Cu}_{2} \mathrm{O}$ is a high refractive index semiconductor ( 2.6 in NIR) which along with metallic shell provides larger visible to NIR tunability in plasmonic resonances compared to other semiconductors $^{21}$. Current interest in the design of SERS substrates is in metal- dielectric-metal multilayer structures with a thin graphene spacer layer which enables efficient coupling of plasmons with the metallic substrates ${ }^{22}$.

The aim of our present work is to model a novel and efficient NIR SERS substrate with large SERS field enhancement factor values at NIR excitation wavelength of $1064 \mathrm{~nm}$. In general, fluorophores used in biological applications - Thioflavin, Cyanine dyes etc. have strong emission within $400 \mathrm{~nm}$ to $750 \mathrm{~nm}$ wavelength range $\mathrm{e}^{23,24}$. Longer excitation wavelength of $1064 \mathrm{~nm}$ is hence chosen to avoid the overwhelming fluorescence background from fluorophores. SERS enhancement in graphene monolayer and NIR SERS by hollow Au nanotags are 
proposed earlier ${ }^{25,26}$. Plasmon resonances below $800 \mathrm{~nm}$ are made use of in the above works which is far below the excitation wavelength $1064 \mathrm{~nm}$. Here we propose a layered NIR SERS substrate with monolayer of $\mathrm{Cu}_{2} \mathrm{O}-\mathrm{Au}$ core-shell particles on Au substrate separated by $1 \mathrm{~nm}$ thick graphene layer. Layered structure is designed in such a way that the plasmon resonance exactly matches with $1064 \mathrm{~nm}$ which can provide enhanced NIR SERS properties. Mie computations and FDTD simulations are used to explore the potential of the proposed structure in NIR SERS applications. Mie calculations using MieLab software is used for the plasmon resonance study of single core-shell particle systems. MieLab software can only be used for the study of single particle systems. Due to this limitation, further modelling of multi core-shell particle embedded SERS substrate is carried out using Lumerical FDTD simulations. Mie theory used for the study of absorption efficiencies of core-shell particles is discussed in the next section.

\section{Absorption Efficiency of $\mathrm{Cu}_{2} \mathrm{O}$ - Au Core-Shell Particles}

Mie theory in the modified form for core-shell particles is used for the calculation of the absorption efficiency of $\mathrm{Cu}_{2} \mathrm{O}-\mathrm{Au}$ core-shell particles in the near infra-red region ${ }^{27}$. According to Mie theory,

$$
\begin{gathered}
\mathrm{Q}_{\mathrm{sca}}=\frac{2}{z^{2}} \sum_{l=1}^{\infty}(2 l+1)\left(\left|a_{l}\right|^{2}+\left|b_{l}\right|^{2}\right) \\
\mathrm{Q}_{\mathrm{ext}}=\frac{2}{z^{2}} \operatorname{Re} \sum_{\mathrm{l}=1}^{\infty}(2 \mathrm{l}+1)\left(\mathrm{a}_{\mathrm{l}}+\mathrm{b}_{1}\right) \\
\mathrm{Q}_{\mathrm{abs}}=\mathrm{Q}_{\mathrm{ext}}-\mathrm{Q}_{\mathrm{sca}}
\end{gathered}
$$

where $Q_{s c a}, Q_{a b s}$ and $Q_{e x t}$ are the scattering, absorption and extinction efficiencies of particles, $\mathrm{z}$ is the size parameter $=\frac{2 \pi R m}{\lambda}, R$ is the radius of the particle, $\lambda$ is the wavelength of light, $m=\frac{n_{s}}{n_{m}}$ where $n_{s}$ is the refractive index of the spherical particle and $n_{m}$ is the refractive index of the medium and $a_{l}$ and $b_{l}$ are the Mie coefficients.

For core-shell particles (core radius $a$ and outer radius $b$ ) with core refractive index $m_{1}$ and shell refractive index $m_{2}$, Mie coefficients $a_{l}$ and $b_{l}$ are calculated using the modified relations ${ }^{21}$,

$$
\begin{array}{r}
a_{l}=\frac{\psi_{l}(y)\left[\psi_{l}^{\prime}\left(m_{2} y\right)-D_{l} \zeta_{l}^{\prime}\left(m_{2} y\right)\right]-\psi_{l}^{\prime}(y)\left[\psi_{l}\left(m_{2} y\right)-D_{l} \zeta_{l}\left(m_{2} y\right)\right]}{\chi_{l}(y)\left[\psi_{l}^{\prime}\left(m_{2} y\right)-D_{l} \zeta_{l}^{\prime}\left(m_{2} y\right)\right]-\chi_{l}^{\prime}(y)\left[\psi_{l}\left(m_{2} y\right)-D_{l} \zeta_{l}\left(m_{2} y\right)\right]} \\
b_{l}=\frac{m_{2} \psi_{l}(y)\left[\psi_{l}^{\prime}\left(m_{2} y\right)-G_{l} \zeta_{l}^{\prime}\left(m_{2} y\right)\right]-\psi_{l}^{\prime}(y)\left[\psi_{l}\left(m_{2} y\right)-G_{l} \zeta_{l}\left(m_{2} y\right)\right]}{m_{2} \chi_{l}(y)\left[\psi_{l}^{\prime}\left(m_{2} y\right)-G_{l} \zeta_{l}^{\prime}\left(m_{2} y\right)\right]-\chi_{l}^{\prime}(y)\left[\psi_{l}\left(m_{2} y\right)-G_{l} \zeta_{l}\left(m_{2} y\right)\right]}
\end{array}
$$

where,

$$
\begin{aligned}
& \mathrm{D}_{1}=\frac{m_{2} \psi_{l}\left(m_{2} x\right) \psi_{l}^{\prime}\left(m_{1} x\right)-m_{1} \psi_{l}^{\prime}\left(m_{2} x\right) \psi_{l}\left(m_{1} x\right)}{m_{2} \zeta_{l}\left(m_{2} x\right) \psi_{l}^{\prime}\left(m_{1} x\right)-m_{1} \zeta_{l}^{\prime}\left(m_{2} x\right) \psi_{l}\left(m_{1} x\right)} \\
& \mathrm{G}_{1}=\frac{m_{2} \psi_{l}\left(m_{1} x\right) \psi_{l}^{\prime}\left(m_{2} x\right)-m_{1} \psi_{l}^{\prime}\left(m_{1} x\right) \psi_{l}\left(m_{2} x\right)}{m_{2} \psi_{l}\left(m_{1} x\right) \zeta_{l}^{\prime}\left(m_{2} x\right)-m_{1} \psi_{l}^{\prime}\left(m_{1} x\right) \zeta_{l}\left(m_{2} x\right)}
\end{aligned}
$$

For each angular momentum $l$, the shift in the plasmon resonances of core-shell particles is in accordance with the relation ${ }^{15}$,

$$
\omega_{l \pm}^{2}=\frac{\omega_{p}^{2}}{2}\left[1 \pm \frac{1}{(2 l+1)} \sqrt{1+4 l(l+1)\left(\frac{a}{b}\right)^{2 l+1}}\right]
$$

$\omega_{l+}$ and $\omega_{l-}$ represent the frequencies of antisymmetric and symmetric modes, $\omega_{p}$ is the bulk plasma frequency and $\mathrm{a}$ and $\mathrm{b}$ are the inner and outer radii of the shell ${ }^{28}$.

$\mathrm{Q}_{\mathrm{abs}}$ values of $\mathrm{Cu}_{2} \mathrm{O}$ - Au core-shell particles in the near infra-red region are calculated using MieLab software. MieLab is a dedicated software to calculate the absorption and scattering properties single core-shell particles. FDTD can also be used for similar studies without any discrepancy of the results. Figure 1(a) shows the comparison of absorption efficiency calculations using MieLab and lumerical FDTD softwares. Absorption efficiency is calculated for $\mathrm{Cu}_{2} \mathrm{O}$ - Au core-shell particle with core radius $60 \mathrm{~nm}$ and shell thickness $10 \mathrm{~nm}$ using both MieLab and lumerical FDTD softwares. It is observed that there is no discernible disparity in the results obtained using both the softwares. The peak values are observed to be the same in both the simulations. $\mathrm{Q}_{\mathrm{abs}}$ value obtained using FDTD simulation (0.14) is found to be comparable with the value obtained using MieLab simulation (0.15). Figure 1(b) shows the variation in Mie and FDTD calculations for the entire Au shell thickness values.

For the ease of simulation we have used MieLab for single particle studies. It is not possible to use MieLab for multiparticle systems. Hence we have used FDTD for further modelling of layered substrates and visualization of electric field. Refractive index data required for simulation for $\mathrm{Au}$ and $\mathrm{Cu}_{2} \mathrm{O}$ are obtained from Johnson and Christy data ${ }^{29}$ and Querry et al. ${ }^{30}$ respectively. We have performed Mie calculations on various aspect ratios of 

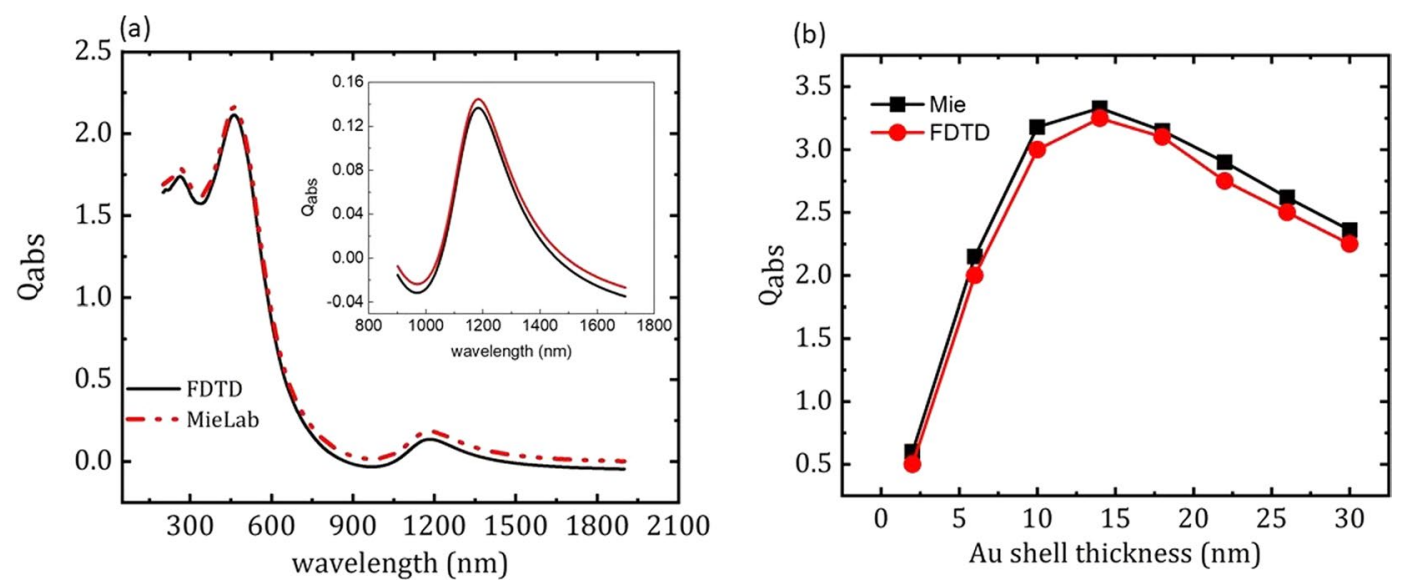

Figure 1. (a) Comparison between $\mathrm{Q}_{\mathrm{abs}}$ values of $\mathrm{Cu}_{2} \mathrm{O}(60 \mathrm{~nm})-\mathrm{Au}(10 \mathrm{~nm})$ core-shell particle calculated using FDTD and MieLab softwares. Inset shows comparison of $\mathrm{Q}_{\mathrm{abs}}$ values for $\mathrm{Cu}_{2} \mathrm{O}(50 \mathrm{~nm})$-Au core-shell particles.

(b) variation in Mie and FDTD calculations for the entire Au shell thickness values.

\begin{tabular}{|c|c|c|c|}
\hline \multirow{2}{*}{$\begin{array}{l}\text { Au shell } \\
\text { thickness } \\
(\mathrm{nm})\end{array}$} & \multicolumn{3}{|l|}{$\lambda(\mathbf{n m})$} \\
\hline & $\mathrm{Cu}_{2} \mathrm{O}(40 \mathrm{~nm})-\mathrm{Au}$ & $\mathrm{Cu}_{2} \mathrm{O}(50 \mathrm{~nm})-\mathrm{Au}$ & $\mathrm{Cu}_{2} \mathrm{O}(60 \mathrm{~nm})-\mathrm{Au}$ \\
\hline 2 & 1325 & 1500 & 1630 \\
\hline 6 & 815 & 1040 & 1100 \\
\hline 10 & 630 & 850 & 905 \\
\hline 14 & 585 & 775 & 830 \\
\hline 18 & 550 & 735 & 784 \\
\hline 22 & 535 & 710 & 750 \\
\hline 26 & 520 & 690 & 732 \\
\hline 30 & 505 & 675 & 712 \\
\hline
\end{tabular}

Table 1. Plasmon resonance tunability data of $\mathrm{Cu}_{2} \mathrm{O}-\mathrm{Au}$ core-shell particles with different core radii and $\mathrm{Au}$ shell thicknesses.

$\mathrm{Cu}_{2} \mathrm{O}$-Au core-shell particles. Table 1 shows plasmon resonance positions obtained for $\mathrm{Cu}_{2} \mathrm{O}-\mathrm{Au}$ core-shell particles with core radius $40 \mathrm{~nm}, 50 \mathrm{~nm}$ and $60 \mathrm{~nm}$ and with Au shell thickness in each case varying from $2 \mathrm{~nm}$ to $30 \mathrm{~nm}$ in steps of $4 \mathrm{~nm}$. Plasmon resonance tunability with increase in $\mathrm{Au}$ shell thickness for $\mathrm{Cu}_{2} \mathrm{O}(40 \mathrm{~nm})-\mathrm{Au}$, $\mathrm{Cu}_{2} \mathrm{O}(50 \mathrm{~nm})-\mathrm{Au}$ and $\mathrm{Cu}_{2} \mathrm{O}(60 \mathrm{~nm})-\mathrm{Au}$ is observed to be from $1325 \mathrm{~nm}$ to $505 \mathrm{~nm}, 1500 \mathrm{~nm}$ to $675 \mathrm{~nm}$ and $1630 \mathrm{~nm}$ to $712 \mathrm{~nm}$, respectively.

Among the different aspect ratios, $\mathrm{Cu}_{2} \mathrm{O}$ - Au core-shell particle with core radius $50 \mathrm{~nm}$ and $\mathrm{Au}$ shell thickness $(2 \mathrm{~nm}$ to $30 \mathrm{~nm})$ are found to have tunable plasmonic resonance within the desired biological window of $650 \mathrm{~nm}$ to $1350 \mathrm{~nm}$ (Fig. 2(a)) and the corresponding $\mathrm{Q}_{\mathrm{abs}}$ and $\mathrm{Q}_{\mathrm{sca}}$ values are shown in Fig. 2(b). From Fig. 2(a) it can be inferred that the plasmon resonances of particles get blue shifted with increase in shell thickness (Eq. 8). For $\mathrm{Cu}_{2} \mathrm{O}$ $(50 \mathrm{~nm})$ - Au core-shell particles, plasmon resonances are found to be tunable from $675 \mathrm{~nm}$ to $1500 \mathrm{~nm}$ which falls within the desired NIR biological window. Absorption efficiency increases with increase in shell thickness till $14 \mathrm{~nm}$ beyond which the $\mathrm{Q}_{\text {abs }}$ reduces (Fig. 2(b)) since the coupling between spherical and cavity plasmons gradually reduces at larger thicknesses. Meanwhile, $\mathrm{Q}_{\mathrm{sca}}$ increases with increase in shell thickness and overrides $\mathrm{Q}_{\mathrm{abs}}$ for larger shell thicknesses (above $25 \mathrm{~nm}$ ). From Fig. 2(b) it can be seen that for $\mathrm{Cu}_{2} \mathrm{O}(50 \mathrm{~nm})$ - Au core-shell particle with shell thickness $6 \mathrm{~nm}$, plasmon resonance is at $1040 \mathrm{~nm}$ which is very close to the desired excitation of $1064 \mathrm{~nm}$.

\section{FDTD Simulations On $\mathrm{Cu}_{2} \mathrm{O}(50 \mathrm{~nm})$-Au Core-Shell Particles}

FDTD simulations are performed using Lumerical software to study the electric field distribution over $\mathrm{Cu}_{2} \mathrm{O}$ $(50 \mathrm{~nm})-\mathrm{Au}$ core-shell particle at $1064 \mathrm{~nm}$ (Fig. 3(a-f)). Simulations are performed by considering air as the surrounding medium. A gradual enhancement in the electric field around the particle with the increase in Au shell thickness is observed till $6 \mathrm{~nm}$ where the field intensity is maximum as the plasmon resonance at $6 \mathrm{~nm}$ shell thickness $(1040 \mathrm{~nm})$ is close to the excitation wavelength of $1064 \mathrm{~nm}$. As the plasmon resonances move farther from the excitation wavelength, a gradual decrease in the near field is observed. We could also observe an abnormal field distribution in Fig. 3b.

In Fig. 3b, the thickness of Au shell is $2 \mathrm{~nm}$ (very close to the quantum regime) where the transverse motion of conduction electrons is quantized. Such quantum size effect results in the formation of two groups of electrons. 
(a)

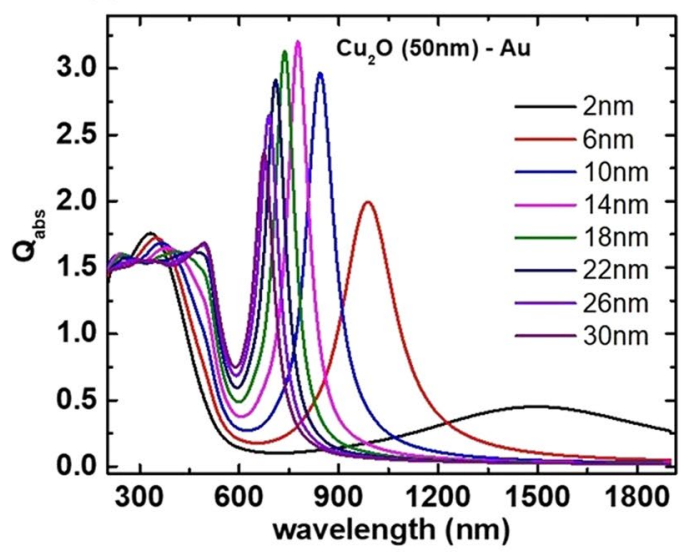

(b)

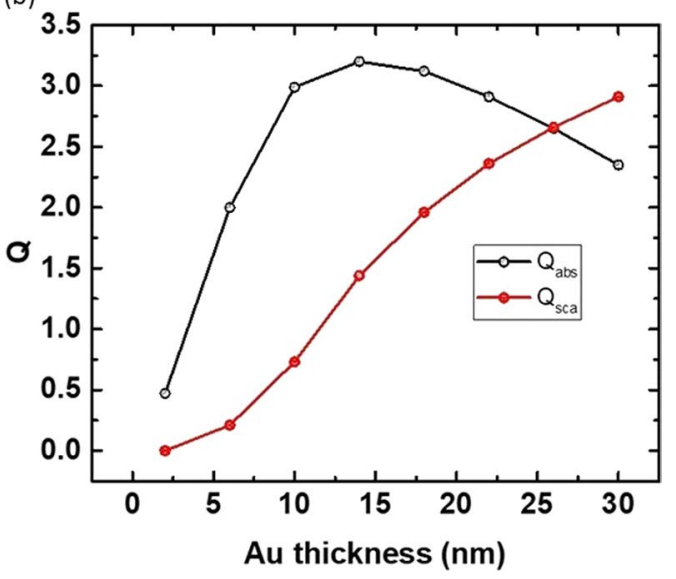

Figure 2. (a) Absorption efficiency vs. wavelength plots of $\mathrm{Cu}_{2} \mathrm{O}(50 \mathrm{~nm})$-Au core-shell particles with different Au shell thicknesses, (b) Absorption and scattering efficiency vs. shell thickness plots for $\mathrm{Cu}_{2} \mathrm{O}(50 \mathrm{~nm})$ $\mathrm{Au}$ core-shell particles. Yellow arrow indicates the $\mathrm{Q}_{\mathrm{abs}}$ value obtained for $\mathrm{Cu}_{2} \mathrm{O}(50 \mathrm{~nm})-\mathrm{Au}(6 \mathrm{~nm})$ at the resonance wavelength of $1040 \mathrm{~nm}$ which is very close to the desired excitation of $1064 \mathrm{~nm}$.
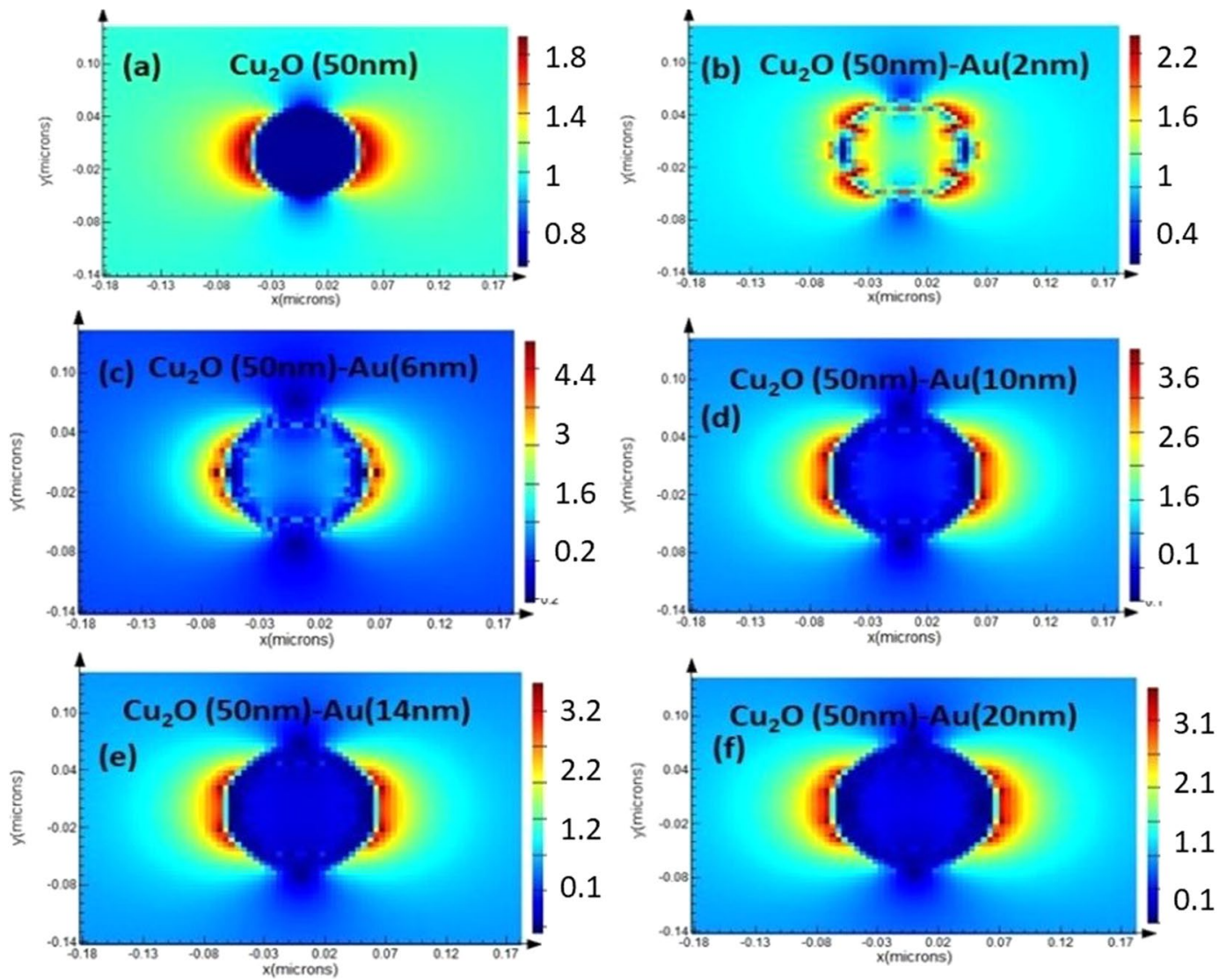

Figure 3. Electric field distribution (|E|) around $\mathrm{Cu}_{2} \mathrm{O}-\mathrm{Au}$ core-shell particles at $1064 \mathrm{~nm}$ excitation for Au shell thickness $0 \mathrm{~nm}(\mathbf{a}), 2 \mathrm{~nm}(\mathbf{b}), 6 \mathrm{~nm}(\mathbf{c}), 10 \mathrm{~nm}(\mathbf{d}), 14 \mathrm{~nm}(\mathbf{e})$ and $20 \mathrm{~nm}(\mathbf{f})$.

One group provides non local contribution to the electromagnetic field response which can be explained classically and also can be studied using FDTD simulations. The other group executes quantum transition between states which are in resonance with the external wave. This can only be explained using the quantum approach and is not possible using FDTD which uses classical approach to solve Maxwell's equations. Abnormal field distribution observed in Fig. 3 b is hence due to the quantum size effect ${ }^{15}$. 


\section{FDTD Simulations On NIR Absorption Enhancement of $\mathrm{Cu}_{2} \mathrm{O}(50 \mathrm{~nm})$ - Au Particles}

We have tried further to improve the NIR absorption efficiency by distributing $\mathrm{Cu}_{2} \mathrm{O}$ - Au core-shell particles on Au substrate using a graphene spacer layer. Graphene is chosen as spacer layer as it is a good absorber of NIR in combination with plasmonic nanostructures. It helps to effectively reduce reflections at substrate-particle interface and also renders efficient coupling of localized surface plasmons of core-shell particles with the Au substrate $^{31}$. Graphene layer of thickness $1 \mathrm{~nm}$ (approximately three layers of graphene) is designed on Au substrate of thickness $50 \mathrm{~nm}$.

Optimization of graphene spacer layer is done using FDTD simulations and the results are shown in Fig. 4. Simulations are performed with one to five layers of graphene as spacer layer. Electric field enhancement between two $\mathrm{Cu}_{2} \mathrm{O}(50 \mathrm{~nm})-\mathrm{Au}(6 \mathrm{~nm})$ core-shell particles is studied in each case using two field monitors along $\mathrm{XZ}$ and $\mathrm{YZ}$ directions. Field intensity between the particles is observed to be the highest with three layers of graphene spacer which corresponds to an approximate thickness of $1 \mathrm{~nm}$ (Fig. 4(e,f)). Hence we have used the optimized thickness of $1 \mathrm{~nm}$ for graphene spacer in all simulations

Figure 5 shows the schematic of the proposed layered structure. Design of the structure and the study of its NIR absorption properties are performed using Lumerical FDTD solutions. $\mathrm{Cu}_{2} \mathrm{O}(50 \mathrm{~nm})-\mathrm{Au}$ core-shell particles are selected for designing the NIR absorber due to their large $\mathrm{Q}_{\mathrm{abs}}$ values in the NIR region. Optimized Au shell is $6 \mathrm{~nm}$ for maximum absorption at $1064 \mathrm{~nm}$ for single $\mathrm{Cu}_{2} \mathrm{O}(50 \mathrm{~nm})$ - Au core-shell particle. But the absorption scenario becomes entirely different when $\mathrm{Cu}_{2} \mathrm{O}$ - Au core-shell particles are distributed over the $\mathrm{Au}$ substrate. Plasmonic coupling between Au substrate and core-shell particles via graphene spacer layer significantly modifies the effective absorption by the designed structure. Hence the NIR absorption properties are further studied for different Au shell thickness values for layered structure. Single layer of $\mathrm{Cu}_{2} \mathrm{O}(50 \mathrm{~nm})-\mathrm{Au}$ particles are uniformly distributed over the graphene layer and the structure is then irradiated with NIR source (power $=1 \mathrm{~mW}$ ). Two different power monitors are used to collect the transmitted and reflected signals from the structure when irradiated with plane wave source $(\lambda=0.7 \mu \mathrm{m}$ to $2 \mu \mathrm{m})$. Perfectly matched layer (PML) boundary condition is employed in all simulations. The mesh size is taken as $0.2 \mathrm{~nm}$ which is well below the thickness of the spacer layer. The incident polarization is parallel to the substrate.

\section{Effect of Au Substrate On Plasmon Resonance of $\mathrm{Cu}_{2} \mathrm{O}(50 \mathrm{~nm})$-Au Particles}

In order to confirm the influence of Au substrate on NIR absorption, FDTD simulations are performed for two different configurations - $\mathrm{Cu}_{2} \mathrm{O}(50 \mathrm{~nm})$ particles without Au substrate and $\mathrm{Cu}_{2} \mathrm{O}(50 \mathrm{~nm})$ particles on $\mathrm{Au}$ substrate. Figure 6 shows absorbance of $\mathrm{Cu}_{2} \mathrm{O}(50 \mathrm{~nm})$ in the presence and absence of Au substrate. Plasmonic field due to $\mathrm{Au}$ substrate is found to have a huge influence on the NIR absorption of $\mathrm{Cu}_{2} \mathrm{O}$ and is reflected as a clear enhancement in the NIR absorption over the entire NIR region. To prove the enhanced plasmonic coupling of core-shell particles with the substrate in the presence of spacer graphene layer, we have modelled two systems in which two $\mathrm{Cu}_{2} \mathrm{O}(50 \mathrm{~nm})-\mathrm{Au}(6 \mathrm{~nm})$ particles are distributed on Au substrate with and without $1 \mathrm{~nm}$ thick spacer graphene layer. The excitation wavelength is chosen as $1064 \mathrm{~nm}$ in FDTD simulations. Field distribution in the XY and YZ directions without and with the spacer layer are shown in Fig. 7(a-d), respectively. Electric field between the particles is found to enhance by around $40 \%$, and between particles and substrate by around $14 \%$ in the presence of graphene spacer layer thereby validating the stronger plasmonic coupling in this case compared to the bare Au substrate.

\section{NIR Absorption in $\left(\mathrm{Cu}_{2} \mathrm{O}(50 \mathrm{~nm})-\mathrm{Au}\right)$-Graphene- Au Layered Structure}

Further, FDTD simulations are performed on the layered structure shown in Fig. 5 by varying the thickness of the $\mathrm{Au}$ shell. Figure 8 shows the absorbance of the layered structure with $\mathrm{Cu}_{2} \mathrm{O}(50 \mathrm{~nm})$ - Au core-shell particles with different Au shell thicknesses. Huge enhancement in absorbance is observed in the NIR region due to the plasmonic coupling between $\mathrm{Cu}_{2} \mathrm{O}$ - Au with $\mathrm{Au}$ substrate through graphene spacer layer. We could observe a gradual enhancement in NIR absorption over the entire range $0.7 \mu \mathrm{m}$ to $1.6 \mu \mathrm{m}$ when the Au shell is added which is the highest at $30 \mathrm{~nm}$ beyond which it is a constant. NIR absorption in the window $0.9 \mu \mathrm{m}$ to $1.1 \mu \mathrm{m}$ for $\left(\mathrm{Cu}_{2} \mathrm{O}\right.$ $(50 \mathrm{~nm})-\mathrm{Au})$ - Graphene - Au layered structure increases by $18 \%$ compared to $\left(\mathrm{Cu}_{2} \mathrm{O}(50 \mathrm{~nm})\right)$ - Graphene - $\mathrm{Au}$ layered structures. Increase in absorption in the specified window is attributed to the effective plasmonic coupling between Au substrate and core - shell particles. Local field around the core - shell particle has contribution from both the localized plasmonic field and the incident electric field. Enhancement in NIR absorption due to Au shell results in the formation of hot spots with stronger local electric field confinement between the core-shell particles. It is inferred from simulations that the hotspots provide significant enhancement factor values which are proportional to the fourth power of locally generated electric field. Generation of such strong hotspots enable SERS detection of biomolecules even with very low Raman cross sections. Our specific interest is in the region $0.9 \mu \mathrm{m}$ to $1.1 \mu \mathrm{m}$ where we could observe a new plasmonic peak originating at higher Au shell thicknesses due to the effective plasmonic coupling between the particles and the substrate. At lower Au shell thickness values, the dipolar and quadrapolar resonances of core-shell particles are far apart where dipolar resonances fall in the IR and quadrapolar resonances fall in the UV region. As the thickness of Au shell increases, quadrapolar resonances get red shifted towards visible region while blue shift occurs to dipolar resonances to visible region making both the resonances much closer. This results in the coupling between these modes causing enhanced effective plasmonic absorption over a wide range and formation of new plasmonic peaks. Such a strong plasmonic absorption within the NIR biological window is highly useful for sensing applications particularly sensing based on NIR surface enhanced Raman spectroscopy (SERS). The possibility of using $\left(\mathrm{Cu}_{2} \mathrm{O}-\mathrm{Au}\right)$ - graphene - Au layered structures as NIR SERS substrate using FDTD simulations is studied further. 

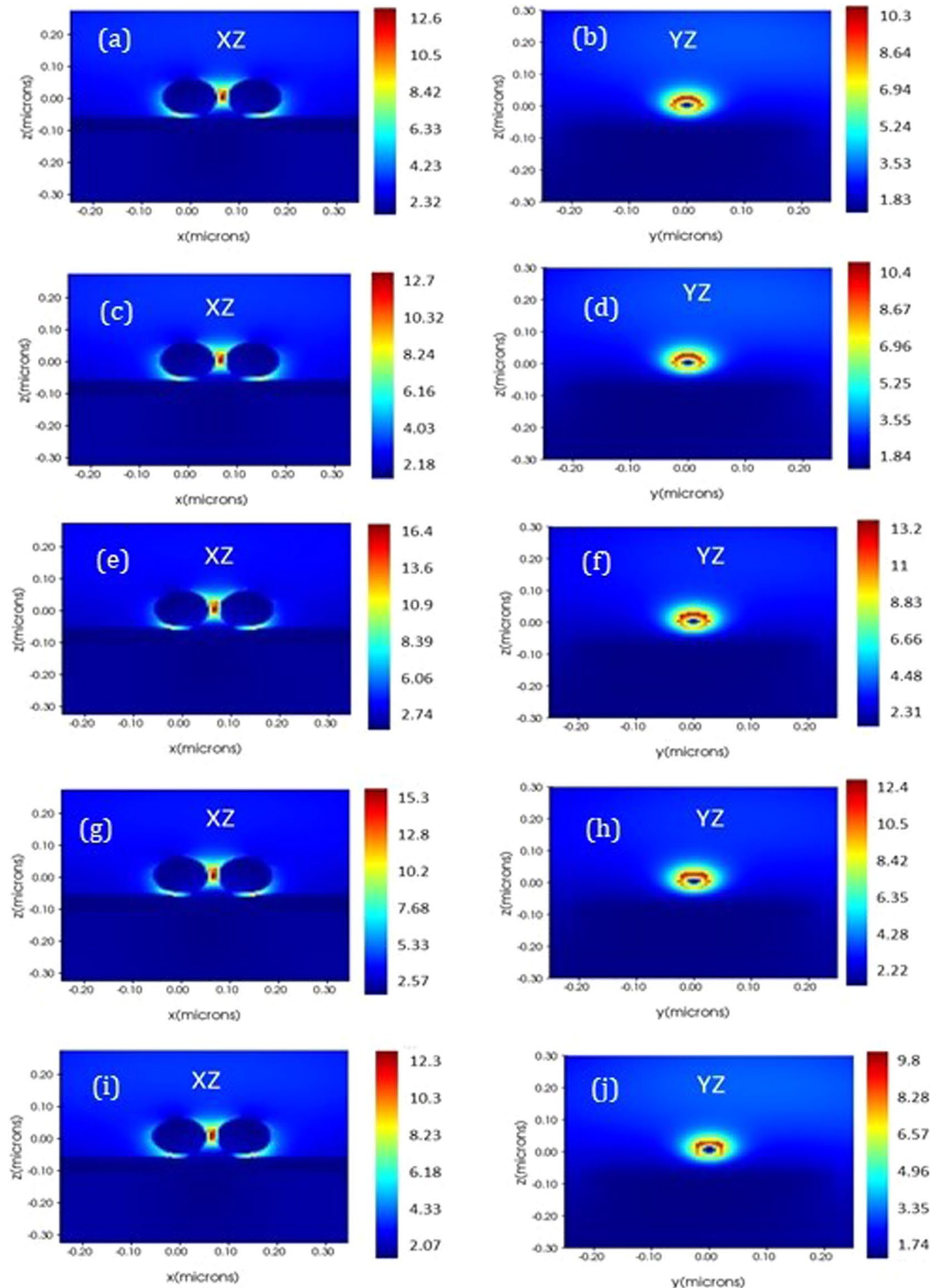

Figure 4. Electric field distribution around $\mathrm{Cu}_{2} \mathrm{O}-\mathrm{Au}$ core-shell particles at varying thickness of graphene spacer layer. Figure 4(a,c,e,g,i) show field distribution in XZ direction and 4(b,d,f,h,j) in YZ direction with one, two, three, four and five layers of graphene spacer layers respectively.

\section{FDTD Simulations on SERS activity of $\mathrm{Cu}_{2} \mathrm{O}-\mathrm{Au}-\mathrm{Graphene-Au}$ Multilayer Substrate}

FDTD simulations are further used to study the scattering enhancement in $\mathrm{Cu}_{2} \mathrm{O}(50 \mathrm{~nm})-\mathrm{Au}$ particles when they are kept on Au substrate with graphene spacer layer. Scattering enhancement factor here is defined as $\left(\mathrm{E} / \mathrm{E}_{0}\right)^{4}$ where $\mathrm{E}$ is the maximum local electric field and $\mathrm{E}_{0}$ is the incident electric field. Gap between $\mathrm{Cu}_{2} \mathrm{O}(50 \mathrm{~nm})-\mathrm{Au}$ particles and also that between $\mathrm{Au}$ substrate and $\mathrm{Cu}_{2} \mathrm{O}(50 \mathrm{~nm})$ - Au particles are maintained as $1 \mathrm{~nm}$ in all simulations. This enabled the plasmons from the particles as well as the substrate interfere constructively to produce highly enhanced local electric field regions within the gaps called hotspots. The excitation source of wavelength 


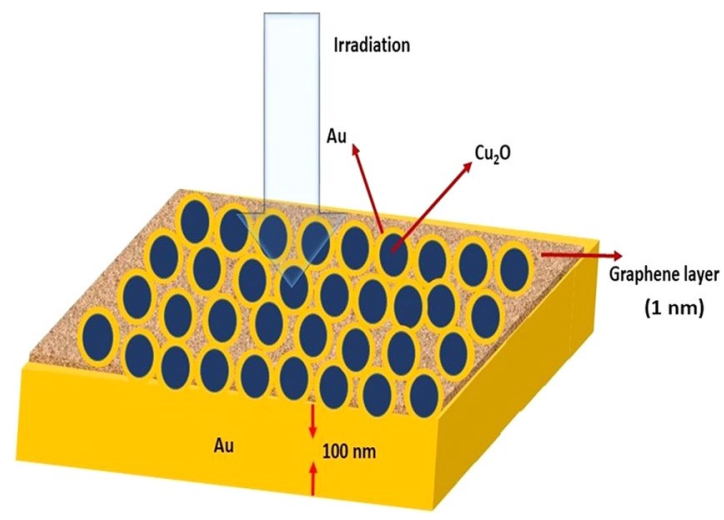

Figure 5. Schematic of $\left(\mathrm{Cu}_{2} \mathrm{O}-\mathrm{Au}\right)$ - Graphene - Au layered structure.

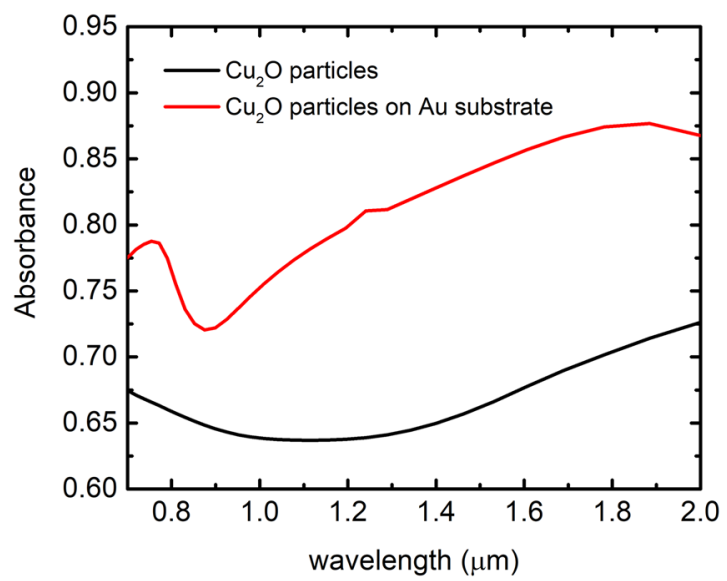

Figure 6. Absorbance of $\mathrm{Cu}_{2} \mathrm{O}$ particles in air (black) and $\mathrm{Cu}_{2} \mathrm{O}$ particles on Au substrate (red).

$1064 \mathrm{~nm}$ to study the NIR SERS property of the layered structure is Total - field scattered - field. It helps to separate the scattered field from the incident field and helps to avoid the reflections from the simulation boundaries.

Simulations are carried out for various Au shell thicknesses ranging from $2 \mathrm{~nm}$ to $30 \mathrm{~nm}$ and the scattering field enhancement factor, which is a measure of SERS activity of the structure, is calculated in each case. Fixed separation of $1 \mathrm{~nm}$ between the particles and that between particles and substrate is maintained in all simulations. SERS enhancement factor $(\mathrm{EF})$ which is a measure of SERS efficiency of substrate is defined as $\left(\mathrm{E} / \mathrm{E}_{0}\right)^{4}$ where $\mathrm{E}$ is the local maximum electric field and $\mathrm{E}_{0}$ is the amplitude of input source electric field. With the addition of $\mathrm{Au}$ shell, $\mathrm{EF}$ is found to increase from $1.24 \times 10^{3}$ to $1.86 \times 10^{8}$ at larger shell thicknesses and the increase is observed to be very fast till the thickness value reaches $22 \mathrm{~nm}$ (Fig. 9). Beyond $22 \mathrm{~nm}$, a slight increase in EF is observed giving rise to a stable order of magnitude 8 at $1064 \mathrm{~nm}$ excitation which points to the possibility of using the proposed structure for NIR SERS applications. Hence the proposed structure will serve as efficient NIR SERS substrate which in particular has applications in bio-sensing where most biomarkers such as fluorescein and AFP have their fluorescence in the visible region.

\section{Conclusion}

We have proposed a novel metal - dielectric - metal layered NIR SERS substrate which can find immense potential in NIR based bio sensing applications. NIR SERS substrate with $\mathrm{Cu}_{2} \mathrm{O}-\mathrm{Au}$ core shell particles distributed over the $\mathrm{Au}$ substrate with graphene spacer layer with optimized aspect ratio $\left(\mathrm{Cu}_{2} \mathrm{O}(50 \mathrm{~nm})-\mathrm{Au}(22 \mathrm{~nm})\right)$ is found to show large electric field enhancement factor of the order of $10^{8}$ at $1064 \mathrm{~nm}$ excitation. Graphene spacer layer enables efficient plasmonic coupling between the upper layers of core-shell particles with Au substrate. Field enhancement factor values which are better than the reported NIR SERS substrates suggest the possibility of using the structure as efficient NIR SERS substrate for various applications. General drawbacks of visible SERS such as fluorescence background, photo bleaching and plasmonic heating which adversely affect the intensity of SERS signals can be overcome by the proposed structure as it is designed for a longer wavelength of $1064 \mathrm{~nm}$.

\section{Methods}

MieLab software is used for the study of plasmon resonance tunability in $\mathrm{Cu}_{2} \mathrm{O}$ - Au core - shell particles. MieLab is a computational package which simulates the scattering of electromagnetic field of multilayered spheres based on Yang's algorithm ${ }^{27}$. Absorption efficiency $\left(Q_{a b s}\right)$ values are calculated for various aspect ratios of $\mathrm{Cu}_{2} \mathrm{O}-\mathrm{Au}$ core - shell particles towards their optimization for maximum absorption in the near Infra-red (NIR) region. 

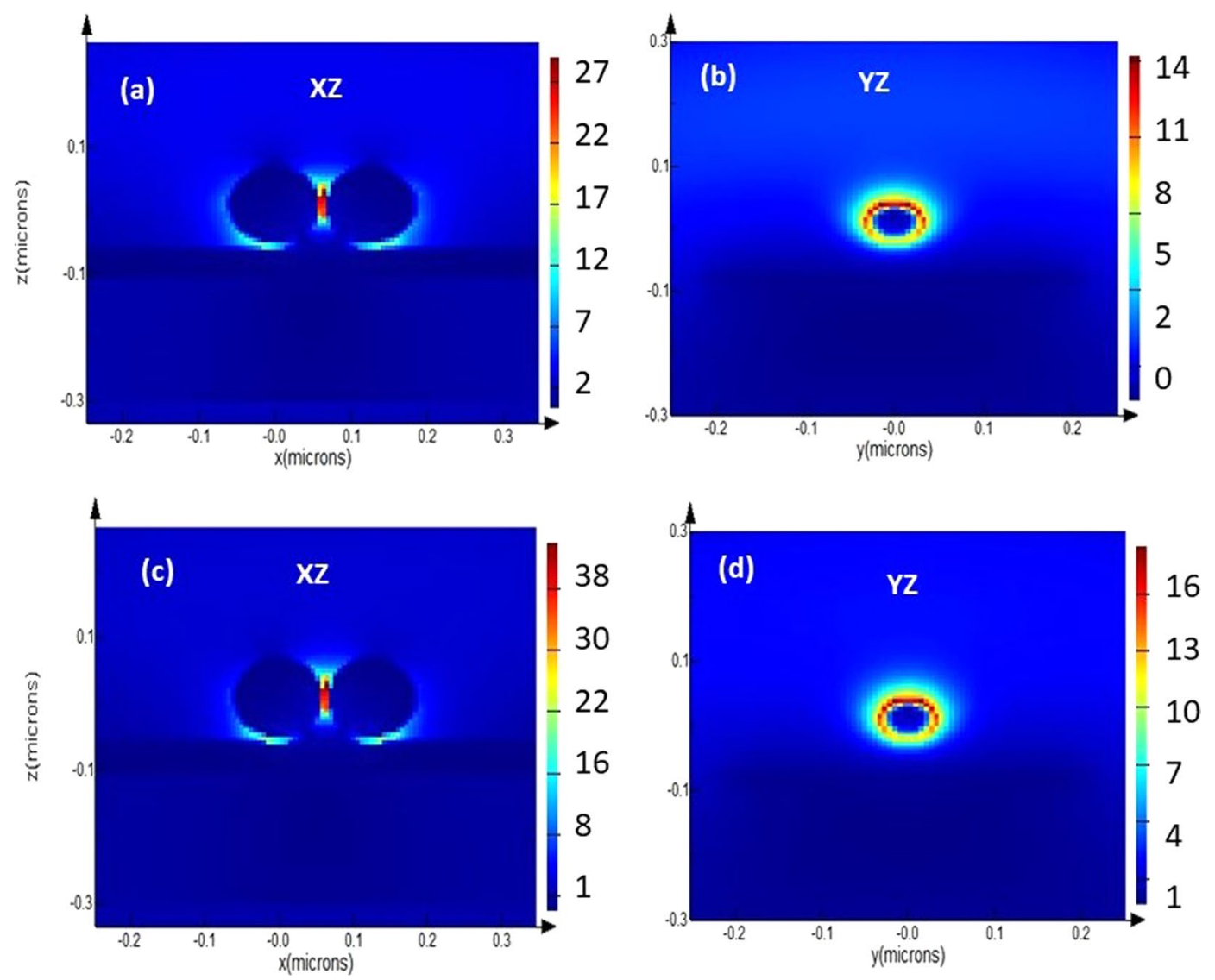

Figure 7. Electric field distribution of $\mathrm{Cu}_{2} \mathrm{O}(50 \mathrm{~nm})-\mathrm{Au}(6 \mathrm{~nm})$ particles on Au substrate in the XZ plane (a) and $\mathrm{YZ}$ plane $(\mathbf{b})$ and that of $\mathrm{Cu}_{2} \mathrm{O}(50 \mathrm{~nm})-\mathrm{Au}(6 \mathrm{~nm})$ particles on Au substrate with $1 \mathrm{~nm}$ thick graphene spacer layer in the XZ plane (c) and YZ plane (d) at an excitation of $1064 \mathrm{~nm}$.

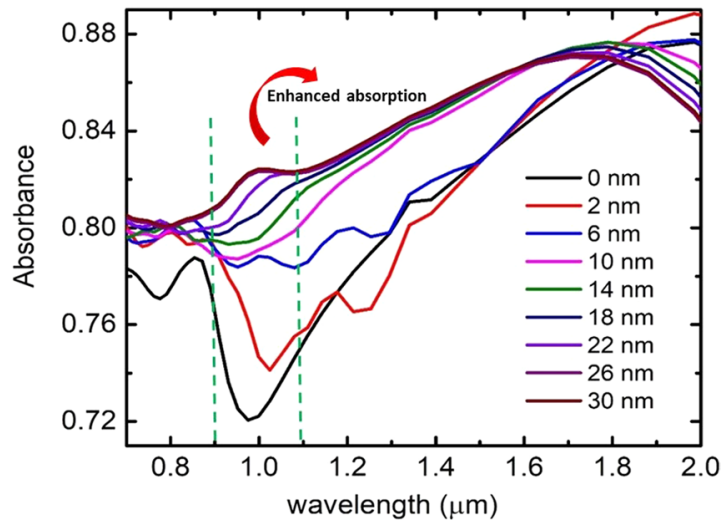

Figure 8. NIR absorbance of $\left(\mathrm{Cu}_{2} \mathrm{O}(50 \mathrm{~nm})\right.$ - $\left.\mathrm{Au}\right)$ - graphene - Au layered structure for different $\mathrm{Au}$ shell thicknesses.

Simulations are performed for three different $\mathrm{Cu}_{2} \mathrm{O}$ core radii $-40 \mathrm{~nm}, 50 \mathrm{~nm}$ and $60 \mathrm{~nm}$, respectively. Au shell thickness is varied from $2 \mathrm{~nm}$ to $30 \mathrm{~nm}$ in steps of $4 \mathrm{~nm}$ for each core radius value. Refractive index values of $\mathrm{Cu}_{2} \mathrm{O}$ and $\mathrm{Au}$ are provided as input parameter for simulations.

Finite difference time domain (FDTD) simulation using lumerical FDTD software is used for visualizing the electric field enhancement at the vicinity of $\mathrm{Cu}_{2} \mathrm{O}-\mathrm{Au}$ core - shell particles. FDTD method is based on the classical solution of Maxwell's curl equations. This method solves Maxwell's equations on a discrete spatial and temporal grid (Yee cell) ${ }^{32}$. Perfectly matched layer (PML) boundary condition is used throughout the simulations. Plane wave source $(\lambda=0.7$ to $2 \mu \mathrm{m})$ is used as the irradiation source. Simulations are performed at a mesh size of $0.2 \mathrm{~nm}$. $\left(\mathrm{Cu}_{2} \mathrm{O}-\mathrm{Au}\right)$ - Graphene - Au layered structure with optimized dimensional parameters are modelled as surface enhanced Raman scattering (SERS) substrate using lumerical FDTD module. Two frequency domain 


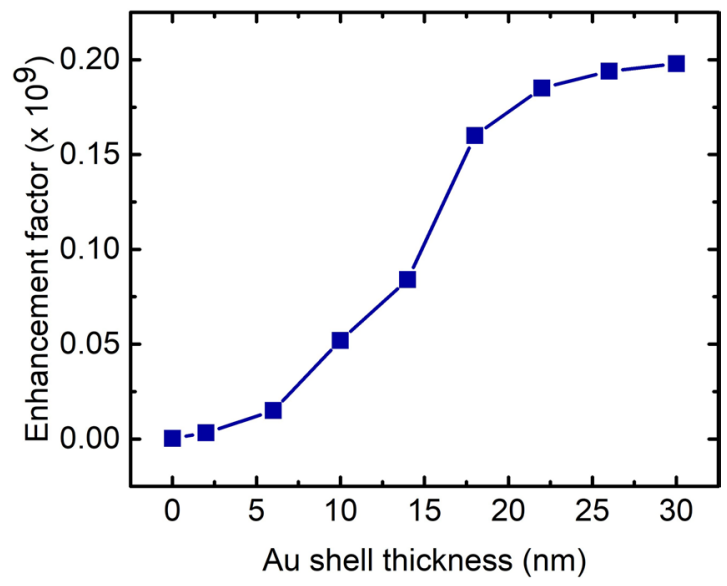

Figure 9. Electric field enhancement factors for $\left(\mathrm{Cu}_{2} \mathrm{O}(50 \mathrm{~nm})\right.$ - $\left.\mathrm{Au}\right)$ - graphene - Au layered structure at different Au shell thicknesses.

field monitors are used for collecting the transmitted and reflected signals when irradiated with the plane wave source. SERS enhancement factor (EF) is simulated for the optimized geometry of the substrate at an excitation wavelength of $1064 \mathrm{~nm}$ using FDTD simulations.

Received: 5 August 2019; Accepted: 14 November 2019;

Published online: 05 March 2020

\section{References}

1. Cheng, X. \& Guan, B. Optical biosensing and bioimaging with porous silicon and silicon quantum dots. Prog. Electromagn. Res. 160, 103-121 (2017).

2. Tian, Z. Q., Ren, B. \& Wu, D. Y. Surface-enhanced Raman scattering: From noble to transition metals and from rough surfaces to ordered nanostructures. J. Phys. Chem. B 106, 9463-9483 (2002).

3. Sujatha, N., Murukeshan, V. M., Ong, L. S. \& Seah, L. K. An all fiber optic system modeling for the gastrointestinal endoscopy: Design concepts and fluorescent analysis. Opt. Commun. 219, 71-79 (2003).

4. Chirumamilla, M., Gopalakrishnan, A., Toma, A., Proietti Zaccaria, R. \& Krahne, R. Plasmon resonance tuning in metal nanostars for surface enhanced Raman scattering. Nanotechnology 25, (2014).

5. Perinchery, S. M. et al. High resolution iridocorneal angle imaging system by axicon lens assisted gonioscopy. Sci. Rep. 6, 1-10 (2016).

6. Ryder, A. G. Surface enhanced Raman scattering for narcotic detection and applications to chemical biology. Curr. Opin. Chem. Biol. 9, 489-493 (2005).

7. Nam, J. M., Oh, J. W., Lee, H. \& Suh, Y. D. Plasmonic Nanogap-Enhanced Raman Scattering with Nanoparticles. Acc. Chem. Res. 49, 2746-2755 (2016).

8. Sharma, B., Frontiera, R. R., Henry, A. I., Ringe, E. \& Van Duyne, R. P. SERS: Materials, applications, and the future. Mater. Today 15, 16-25 (2012)

9. Chua, J. K. \& Murukeshan, V. M. Patterning of twodimensional nanoscale features using gratingbased multiple beams interference lithography. Phys. Scr. 80, (2009).

10. Murukeshan, V. M., Chua, J. K., Tan, S. K. \& Lin, Q. Y. Nano-scale three dimensional surface relief features using single exposure countercpropagating multiple evanescent waves interference phenomenon. Opt. Express 16, 13857 (2008).

11. Álvarez-Puebla, R. A. Effects of the excitation Wavelength on the SERS spectrum. J. Phys. Chem. Lett. 3, 857-866 (2012).

12. Lai, C. H. et al. Near infrared surface-enhanced Raman scattering based on star-shaped gold/silver nanoparticles and hyperbolic metamaterial. Sci. Rep. 7, 1-8 (2017)

13. Greeneltch, N. G. et al. Near-infrared surface-enhanced raman spectroscopy (NIR-SERS) for the identification of eosin Y: Theoretical calculations and evaluation of two different nanoplasmonic substrates. J. Phys. Chem. A 116, 11863-11869 (2012).

14. Liz-Marzán, L. M. Tailoring surface plasmons through the morphology and assembly of metal nanoparticles. Langmuir 22, 32-41 (2006).

15. Gummaluri, V. S., Nair, R. V., Krishnan, S. R. \& Vijayan, C. Femtosecond laser-pumped plasmonically enhanced near-infrared random laser based on engineered scatterers. Opt. Lett. 42, 5002 (2017).

16. Kwizera, E. A., Chaffin, E., Wang, Y. \& Huang, X. Synthesis and properties of magnetic-optical core-shell nanoparticles. RSC Adv. 7, 17137-17153 (2017).

17. Seah, L. K., Dinish, U. S., Ong, S. K., Chao, Z. X. \& Murukeshan, V. M. Time-resolved imaging of latent fingerprints with nanosecond resolution. Opt. Laser Technol. 36, 371-376 (2004).

18. Xia, Y., Matham, M. V., Su, H., Padmanabhan, P. \& Gulyás, B. Nanoparticulate contrast agents for multimodality molecular imaging. J. Biomed. Nanotechnol. 12, 1553-1584 (2016).

19. Rodríguez-Fernández, J., Pastoriza-Santos, I., Pérez-Juste, J., García De Abajo, F. J. \& Liz-Marzán, L. M. The effect of silica coating on the optical response of sub-micrometer gold spheres. J. Phys. Chem. C 111, 13361-13366 (2007).

20. Laaksonen, K. et al. Influence of high-refractive-index oxide cores on optical properties of metal nanoshells. J. Opt. Soc. Am. B 31, 494 (2014).

21. Huang, M. H., Rej, S. \& Chiu, C. Y. Facet-Dependent Optical Properties Revealed through Investigation of Polyhedral Au-Cu2O and Bimetallic Core-Shell Nanocrystals. Small 11, 2716-2726 (2015).

22. Guo, Y. et al. Fabrication of Ag-Cu2O/Reduced Graphene Oxide Nanocomposites as Surface-Enhanced Raman Scattering Substrates for in Situ Monitoring of Peroxidase-Like Catalytic Reaction and Biosensing. ACS Appl. Mater. Interfaces 9, 19074-19081 (2017).

23. Collart, F. R. \& Weiss, S. Bioconj. Chem. Bioconj. Chem. 19, 786 (2008) 
24. Anand, B. G., Dubey, K., Shekhawat, D. S. \& Kar, K. Capsaicin-Coated Silver Nanoparticles Inhibit Amyloid Fibril Formation of Serum Albumin. Biochemistry 55, 3345-3348 (2016).

25. Park, W. H. \& Cheong, H. Exploring the SERS background using a sandwiched graphene monolayer with gap-plasmon junctions. J. Phys. D. Appl. Phys. 49, (2016).

26. Kearns, H., Shand, N. C., Smith, W. E., Faulds, K. \& Graham, D. 1064 nm SERS of NIR active hollow gold nanotags. Phys. Chem. Chem. Phys. 17, 1980-1986 (2015).

27. Peña-Rodríguez, O., González Pérez, P. P. \& Pal, U. MieLab: A Software Tool to Perform Calculations on the Scattering of Electromagnetic Waves by Multilayered Spheres. Int. J. Spectrosc. 2011, 1-10 (2011).

28. Halas, N. J. A Hybridization Model for the Plasmon Response of Complex Nanostructures A Hybridization Model for the. Science (80-.). 302, 419-422 (2015).

29. Johnson, P. B. \& Christy, R. W. Optical Constants of the Noble Metals. Phys. Rev. B 6, 4370-4379 (1972).

30. M. R. Querry. Optical constants, Contractor Report CRDC-CR-85034 (1985).

31. Liu, J.-Q. et al. Tunable Plasmonic Dispersion and Strong Coupling in Graphene Ribbon and Double Layer Sheets Structure. Plasmonics 12, 309-314 (2017).

32. Lesina, A. C., Vaccari, A., Berini, P. \& Ramunno, L. On the convergence and accuracy of the FDTD method for nanoplasmonics. Opt. Express 23, 10481 (2015).

\section{Acknowledgements}

The authors acknowledge NTU, COLE-EDB and Ministry of Education, MoE Singapore (RG 192/17) for the financial support.

\section{Author contributions}

R.V.N. along with V.M.M. conducted the research presented in this manuscript. All computational simulations are performed by R.V.N. Both authors prepared, corrected and finalized the manuscript. V.M.M. supervised the project as principal investigator.

\section{Competing interests}

The authors declare no competing interests.

\section{Additional information}

Correspondence and requests for materials should be addressed to V.M.M.

Reprints and permissions information is available at www.nature.com/reprints.

Publisher's note Springer Nature remains neutral with regard to jurisdictional claims in published maps and institutional affiliations.

Open Access This article is licensed under a Creative Commons Attribution 4.0 International License, which permits use, sharing, adaptation, distribution and reproduction in any medium or format, as long as you give appropriate credit to the original author(s) and the source, provide a link to the Creative Commons license, and indicate if changes were made. The images or other third party material in this article are included in the article's Creative Commons license, unless indicated otherwise in a credit line to the material. If material is not included in the article's Creative Commons license and your intended use is not permitted by statutory regulation or exceeds the permitted use, you will need to obtain permission directly from the copyright holder. To view a copy of this license, visit http://creativecommons.org/licenses/by/4.0/.

(C) The Author(s) 2020 